\title{
Ocorrência e recomendações para o manejo de Sirex noctilio Fabricius (Hymenoptera, Siricidae) em plantios de Pinus patula (Pinaceae) em Minas Gerais, Brasil
}

\author{
Edson Tadeu Iede ${ }^{1} \&$ Ronald Zanetti ${ }^{2}$
}

'EMBRAPA/Florestas, Centro Nacional de Pesquisa de Florestas, Caixa Postal 319, 83411-000, Colombo-PR, Brasil. iedeet@cnpf.embrapa.br 2Departamento de Entomologia, Universidade Federal de Lavras, Caixa Postal 3037, 37200-000, Lavras-MG, Brasil. zanetti@ufla.br

\begin{abstract}
Occurrence and management recommendations of Sirex noctilio Fabricius (Hymenoptera, Siricidae) on Pinus patula (Pinaceae) plantations in the state of Minas Gerais, Brazil. The woodwasp Sirex noctilio Fabricius, 1793 (Hymenoptera, Siricidae) is the most important pest on Pinus spp. in Brazil. It was introduced in the state of Rio Grande do Sul in 1988 and dispersed through the southern states. In 2004 it was detected in São Paulo state. In this work, it is reported the occurrence of $S$. noctilio in the state of Minas Gerais, in January 2005, on commercial areas of Pinus patula. It is discussed some measures that can be adopted to restrict its spread in the southeastern region.
\end{abstract}

KEYWORDS. Forest plantations; quarantine pest; woodwasp.

ABSTRACT. Ocorrência e recomendações para o manejo de Sirex noctilio Fabricius (Hymenoptera, Siricidae) em plantios de Pinus patula (Pinaceae) em Minas Gerais, Brasil. A vespa-da-madeira Sirex noctilio Fabricius, 1793 (Hymenoptera, Siricidae) é a praga mais importante das florestas cultivadas com Pinus spp. no Brasil. Foi introduzida no Rio Grande do Sul em 1988 e sua dispersão ficou restrita aos estados do sul do país até 2004, quando foi detectada em São Paulo. Neste trabalho é relatada a ocorrência de S. noctilio em plantios de Pinus patula em Minas Gerais, em janeiro de 2005. São discutidas algumas medidas que podem ser adotadas para restringir a dispersão de $S$. noctilio na região Sudeste.

PALAVRAS-CHAVE. Praga quarentenária; reflorestamento; vespa-da-madeira.

As plantações de Pinus spp. representam um importante recurso socio-econômico atual e potencial para o Brasil, devido à sua grande participação na cadeia produtiva da madeira, na recuperação de áreas degradadas e na geração de empregos. O Brasil possui 1.840.050 hectares plantados com o gênero Pinus, sendo que 57,6\% dessa área concentram-se nos Estados do Paraná (32,9\%), Rio Grande do Sul $(7,4 \%)$ e Santa Catarina com 17,3\% (SBS 2007).

Uma importante praga dessa cultura é a vespa-da-madeira Sirex noctilio Fabricius, 1793 (Hymenoptera, Siricidae). Essa vespa é considerada uma praga secundária na região de origem (Europa, Ásia e Norte da África). Entretanto nos países em que foi introduzida e se estabeleceu, como na Nova Zelândia (1900), Austrália (1951), Uruguai (1980), Argentina (1985), Brasil (1988), África do Sul (1994) e Chile (2000), tornou-se uma praga primária, causando perdas significativas nos recursos florestais. Mais recentemente, em 2005, foi detectada nos Estados Unidos e Canadá. Na Nova Zelândia provocou perdas de $30 \%$ em 120.000 ha (Rawlings \& Wilson 1948). Na Tasmânia, no final da década de 50, perdeu-se cerca de $40 \%$ das árvores (Taylor 1981). No Uruguai, depois de sua introdução, assim como na Argentina e Brasil, a praga provocou mortalidade de até $60 \%$ em algumas plantações de Pinus taeda.
Na Austrália, depois de um aumento na população da praga, ocorrido no período 1987/89, calcularam-se prejuízos econômicos da ordem de 8 milhões de dólares australianos, com perdas de 5 milhões de árvores (Haugen \& Underdown 1990).

A detecção da vespa-da-madeira em plantações de Pinus spp. do Rio Grande do Sul, em 1988, colocou em risco o patrimônio florestal da região, face os danos que essa praga pode provocar. Atualmente estima-se que a praga esteja afetando cerca de 400.000 ha, causando perdas econômicas em torno de 9 milhões de dólares anuais, quando se considera uma perda de 5 árvores/ha/ano, sem levar em conta a idade da plantação, etc. Na região sudeste, seu primeiro registro foi feito em 2004, no Estado de São Paulo, nos municípios de Jundiaí, Capão Bonito, Itapeva e Itapirapuá Paulista.

Para retardar a dispersão de $S$. noctilio e manter a população dessa praga abaixo do nível de dano econômico, é necessária a adoção de medidas de monitoramento e controle eficazes e contínuas, como as utilizadas pelo Programa Nacional de Controle à Vespa-da-Madeira, que conseguiu reduzir as perdas provocadas pela vespa em mais de $70 \%$.

Os adultos da vespa-da-madeira apresentam dimorfismo sexual muito acentuado. O macho é de cor azul metálico, sendo as asas, a fronte, as pernas anteriores e medianas e os 
segmentos abdominais, do terceiro ao sétimo, de cor laranja. As pernas posteriores são negras. A fêmea apresenta coloração azul escuro metálico, com as pernas e asas de coloração âmbar. Possuem um ovipositor em forma de projeção no final do abdômen, o qual é protegido por uma bainha. Ambos os sexos apresentam um proeminente espinho (cerco), no último segmento abdominal (Iede et al. 1988). As fêmeas ovipositam uma média de 226 ovos, variando de 20 a 430 ovos. Vivem cerca de 4 dias, enquanto que os machos, 5 dias. O período de incubação pode durar de 14 a 28 dias (Carvalho 1992).

Os ovos da vespa-da-madeira são de forma alongada, coloração branca e superfície lisa. Durante a postura, $S$. noctilio pode realizar perfurações simples ou múltiplas no alburno das árvores de Pinus spp., a uma profundidade média de $12 \mathrm{~mm}$ (Madden 1974). Durante a postura, além dos ovos, são introduzidos na árvore, esporos de um fungo simbionte Amylostereum areolatum (Chaillet) Boidin (Agaricomycetidae), o qual provoca o fechamento dos vasos de condução de seiva, durante o processo de morte da árvore. Também é depositada uma mucosecreção, que está contida em uma glândula de muco, localizada na base do ovipositor. Esta mucosecreção provoca mudanças fisiológicas rápidas no metabolismo de Pinus spp., afetando a respiração, transpiração, fotossíntese e divisão celular, favorecendo o estabelecimento do micélio do fungo. O muco e o fungo agem juntos criando um "habitat" favorável para o crescimento contínuo do fungo e alimentação da larva. Ambos levam a árvore à morte (Coutts 1969; Madden 1977).

As larvas são de coloração geral creme, formato cilíndrico, com vestígios de pernas torácicas, fortes mandíbulas denteadas e um espinho supra-anal. Este espinho é utilizado pela larva para comprimir o "frass" (a serragem constituída de uma mistura de fezes, madeira triturada e excreções do inseto), durante a sua atividade alimentar. Logo após a eclosão, a larva inicia a sua alimentação, construindo galerias próximas aos locais de postura. Quando atingem o terceiro ou quarto instar, constroem galerias mais internas na madeira.

As pupas de $S$. noctilio são brancas, do tipo exarata e apresentam um tegumento fino e transparente, tornando-se escurecidas próximo à emergência dos adultos.

Os adultos de $S$. noctilio começam a emergir, geralmente, em meados da primavera (outubro) até o princípio do verão (janeiro), com picos populacionais entre novembro e dezembro. Entretanto, podem ocorrer variações, devido a diferenças nas condições climáticas. Cerca de 2 a $3 \%$ da população apresenta um segundo período de emergência, que pode ocorrer no outono (entre março e abril), em virtude da existência de insetos com ciclo de vida curto. No Brasil, $97 \%$ da população de $S$. noctilio completa o seu desenvolvimento em um ano. Foi observada a existência de ciclos curtos, de três a quatro meses, em toretes em árvores, ou ponteiras de árvores com diâmetro entre 5 e $15 \mathrm{~cm}$ (Reis Filho 1999).

Os principais danos provocados por este inseto são: perfurações na madeira, realizadas por larvas e adultos; deterioração da madeira, devido à ação do fungo A. areolatum; e ocorrência de partes debilitadas nos locais, onde as posturas são realizadas, com o escorrimento de resina, sendo também esta uma porta de entrada de patógenos secundários, como aqueles do gênero Botryodiplodia (Iede et al. 1998).

Os sintomas externos mais visíveis são: progressivo amarelecimento da copa até atingir coloração marromavermelhada; esmorecimento da folhagem e perda das acículas; respingos de resina na casca (em função das perfurações realizadas para a postura) e orifício de emergência de adultos. Os sintomas internos são: presença de manchas marrons ao longo do câmbio (abaixo da casca), causadas pelo fungo $A$. areolatum, e galerias feitas pelas larvas, que possibilita a penetração de agentes secundários. Todos esses fatores comprometem a qualidade da madeira, limitando ou impedindo o seu uso para o mercado (Iede et al. 1998).

Sirex noctilio não é considerada uma praga primária, visto que, outros fatores devem contribuir, inicialmente, para que a árvore se torne atrativa e apresente as condições adequadas para o desenvolvimento do inseto. A atratividade resulta da liberação de hidrocarbonetos monoterpenos pela casca, originários da seiva do floema ou câmbio, seguido por mudanças na permeabilidade da casca (Neumann 1987). Esse fenômeno se dá em locais da planta que se encontram estressados, tendo sido verificado também um declínio na pressão osmótica e a paralisação temporária do crescimento da árvore.

Árvores preferidas pela vespa-da-madeira apresentam um menor diâmetro e encontram-se na condição de dominada, embora tenha sido constatado também, o ataque em árvores dominantes. As árvores atacadas apresentam clorose das acículas e o seu período de aparecimento depende da intensidade do ataque e da suscetibilidade da espécie hospedeira.

Face ao caráter oportunista da praga, a adoção de práticas silviculturais adequadas para manter a sanidade e o vigor dos plantios de pinus, é o princípio fundamental para prevenir ataques severos. Aonde a praga está presente, a principal recomendação é que sejam realizados os desbastes de forma oportuna, a fim de evitar perdas de importância econômica (Iede et al. 1998).

O controle biológico clássico, dentro de uma estratégia de Manejo Integrado de Pragas (MIP) para uma espécie que foi introduzida, é o método mais recomendável para o seu controle. Entre os agentes de controle biológico destacam-se o nematóide Deladenus (=Beddingia) siricidicola (Bedding, 1968) (Nematoda, Neothylenchidae) que esteriliza as fêmeas da vespa-da-madeira, alcançando níveis de parasitismo próximos de 100\% (Iede et al. 1998). O parasitóide de ovos Ibalia leucospoides Hochenwarth, 1785 (Hymenoptera, Ibaliidae) com níveis de parasitismo de 4 a $45 \%$, e os ectoparasitódes de larvas maduras, Megarhyssa nortoni Cresson, 1864 e Rhyssa persuasoria (Linnaeus, 1758) (Hymenoptera, Ichneumonidae), também são organismos recomendáveis para o controle de $S$. noctilio.

A ocorrência de S. noctilio em Camanducaia, Minas Gerais foi observada em janeiro de 2005, na fazenda Levantina, em plantios de $P$. patula que ocupam cerca de 2400 ha, muitos dos quais, com idade avançada. A fazenda possui 11.500 ha, 
sendo 5500 ha ocupados com plantios de espécies de coníferas dos gêneros Cupressus, Cuninghamia e Pinus. Na ocasião foi capturada uma fêmea da vespa e do parasitóide I. leucospoides (Hymenoptera, Ibaliidae), que foram enviadas para identificação. A confirmação da presença do inseto foi feita em agosto de 2006.

Os plantios atacados pela vespa-da-madeira estavam com idades de 12, 19 e 35 anos, todos eles com algum problema silvicultural, desde solos rasos com afloramento de rocha, até problema de estagnação da floresta, devido à falta de desbastes. No plantio de 12 anos de idade de $P$. patula, havia também um ataque da lagarta desfolhadora Glena bipennaria Guenée, 1857 (Lepidoptera, Geometridae). Nessa área, foram encontradas árvores e troncos caídos com orifícios de emergência da vespada-madeira, indicando que o inseto estava presente na área há alguns anos. Verificou-se claramente que as condições edáficas (solos rasos com afloramento de rocha) levaram as árvores ao estresse. Pode-se depreender que o maior problema para as árvores não foi o ataque dos insetos (vespa-da-madeira e a lagarta desfolhadora), mas sim a condição silvicultural do plantio.

Os plantios de cerca de 35 anos de idade apresentavam grande número de árvores mortas atacadas pela vespa-damadeira, contendo orifícios de emergência de insetos adultos, como também galerias com larvas de $S$. noctilio.

$\mathrm{O}$ ataque de $S$. noctilio, na região de Camanducaia, está ocorrendo devido à associação de diferentes fatores, que foram reforçados pela ocorrência de períodos prolongados de seca, causando um déficit hídrico nos plantios. Pôde-se diagnosticar que os plantios estavam muito estressados face a interação idade $\mathrm{x}$ densidade $\mathrm{x}$ sítio. Isso afetou fortemente $\mathrm{o}$ vigor da árvore predispondo-a ao ataque da vespa-da-madeira. Plantios com problemas silviculturais como desbastes atrasados, localizados em sítios ruins, com solos rasos e afloramento de rocha são muito mais afetados pela seca e com isso as árvores tornam-se atrativas à vespa-da-madeira (Iede et al. 1988). Em 2007 a praga foi registrada também, no município de Lavras, MG.

Para o controle da vespa nessa região é preciso estabelecer um programa de controle biológico com a inoculação do nematóide $D$. siricidicola, em pelo menos $20 \%$ das árvores atacadas; instalar árvores-armadilha em locais onde o nível de ataque é abaixo de $1 \%$, entre agosto e setembro, para servirem de pontos de liberação de nematóides; realizar corte raso do plantio de 33 para 34 anos de idade; atualizar os desbastes em talhões que se encontram estagnados, retirando-se as árvores mortas, dominadas, bifurcadas, danificadas por diferentes causas; realizar corte raso em áreas de afloramento de rocha, visto que são locais indevidos para o plantio; fazer obrigatoriamente, um desbaste fitossanitário em talhões com mais de $10 \%$ de árvores atacadas e dependendo da condição do plantio, realizar o corte raso; e finalmente, não realizar operações de poda e desbaste no período de setembro a janeiro em áreas de risco de ataque da vespa-da-madeira.

Agradecimentos. À empresa Companhia Melhoramentos S.A. pelas facilidades e informações fornecidas para a realização do levantamento.

\section{REFERÊNCIAS}

Carvalho, A. G. 1992. Bioecologia de Sirex noctilio F., 1793 (Hymenoptera: Siricidae) em povoamentos de Pinus taeda L. Curitiba, Universidade Federal do Paraná. 131 p. (Tese em Ciências Florestais).

Coutts, M. P. 1969. The mechanism of pathogenicity of Sirex noctilio on Pinus radiata. I. Effects of symbiotic fungus Amylostereum sp. (Thelophoraceae). Australian Journal of Biological Science 22: 915-924, 1969.

Haugen, D. A. \& M. G. Underdown. 1990. Sirex noctilio control program in response to the 1987 Green Triangle outbreak. Australian Forestry 53: 33-40.

Iede, E. T.; S. R. C. Penteado \& J. C. Bisol. 1988. Primeiro registro de ataque de Sirex noctilio em Pinus taeda no Brasil. Circular Técnica EMBRAPA-CNPF n. 20. 12 p.

Iede, E. T.; S. R. C. Penteado \& E. Schaitza. 1998. Programa nacional de controle a vespa-da-madeira no Brasil. p. 43-51. In: Training in the control of Sirex noctilio by the use of natural enemies. Morgantown, USDA Forest Service.

Madden, J. L. 1974. Oviposition behavior of the woodwasp Sirex noctilio F. Australian Journal of Zoology 22: 341-351.

Madden, J. L. 1977. Physiological reactions of Pinus radiata to attack by the woodwasp, Sirex noctilio F. (Hymenoptera: Siricidae). Bulletin of Entomological Research 67: 405-426.

Neumann, F. G.; J. L. Morey \& R. J. Mckimm. 1987. The sirex wasp in Victoria. Victoria, Bulletin of Department of Conservation Forest and Lands 29. $41 \mathrm{p}$.

Rawlings, G. B \& N. M. Wilson. 1948. Sirex noctilio as a beneficial and destructive insect to Pinus radiata. New Zealand Journal of Forestry 6: 1-11.

Reis Filho, W. 1999. Fatores biológicos e comportamentais de Ibalia leucospoides Hochenw (Hymenoptera: Ibaliidae) e de seu hospedeiro Sirex noctilio Fabricius, 1793 (Hymenoptera: Siricidae), visando a otimização do controle biológico natural. Curitiba, Universidade Federal do Paraná. 106p. (Tese em Ciências Biológicas).

SBS - Sociedade Brasileira de Silvicultura. Estatísticas: área plantada com pínus e eucaliptos no Brasil: 2000. São Paulo: 2001. Disponível em: http://www.sbs.org.br/estatisticas.htm Acesso em 10 out 2007.

Taylor, K. L. 1981. The Sirex woodwasp: ecology and control of an introduced forest. p. 231-248. In: Kitching, R.L. \& R.E. Jones (eds). The ecology of pests; some Australian case histories. Melbourne: CSIRO. 254 p. 